ORIGINAL ARTICLE

\title{
Potential risk factors for the development of acute renal failure in preterm newborn infants: a case-control study
}

\author{
L Cataldi, R Leone, U Moretti, B De Mitri, V Fanos, L Ruggeri, G Sabatino, F Torcasio, V Zanardo, \\ G Attardo, F Riccobene, C Martano, D Benini, L Cuzzolin
}

Arch Dis Child Fetal Neonatal Ed 2005;90:F514-F519. doi: 10.1136/adc.2004.060434

See end of article for authors' affiliations

Correspondence to: Dr Cuzzolin, Department of Medicine and Public Health, Section of Pharmacology, University of Verona, Policlinico GB Rossi, Piazzale LA Scuro, 37134 Verona, Italy; laura.cuzzolin@univr.it

Accepted 2 May 2005
Aims: To determine in a case-control study possible associations between the development of acute renal failure in preterm newborns and therapeutic interventions, particularly drug treatments.

Methods: The study population was 172 preterm infants of $<38$ weeks gestation; 71 had acute renal failure and 101 were controls closely matched for gestational age and birth weight. Maternal and neonatal information was collected for both groups through questionnaires and interviews. Routine data on renal variables were also collected. Univariate and multivariate logistic regression analyses were performed.

Results: Very low birthweight infants were at high risk of acute renal failure (79\% of cases were $<1500 \mathrm{~g}$ ). However, the acute renal failure was transient. Mothers of infants with acute renal failure received more drugs during pregnancy and delivery (mainly antibiotics and non-steroidal anti-inflammatory drugs). Of the possible therapeutic interventions, intubation, catheterisation, and phototherapy were mainly applied to case subjects. A low Apgar score and patent ductus arteriosus were diagnosed in a greater percentage of neonates with acute renal failure. Moreover, in the first few days of life and before diagnosis of acute renal failure, case subjects received more drugs (antibiotics, non-steroidal anti-inflammatory drugs, and diuretics) and for a longer time. In the multivariate logistic analysis, medullary hyperechogenicity (odds ratio (OR) 4.491 ; $95 \%$ confidence interval (Cl) 1.879 to 10.731 ) and ceftazidime administration (OR $5.082 ; 95 \% \mathrm{Cl} 1.493$ to 17.297 ) were associated with a greater risk of acute renal failure.

Conclusions: The results suggest the need for careful monitoring of very low birthweight infants and attention to drug treatments, as it is difficult to differentiate between normality and renal failure in the first few days of life.

\footnotetext{
$\mathrm{O}$
} ver the past 20 years, rates of survival of very low birthweight infants have increased because of improved technical and pharmacological interventions. ${ }^{1}$ However, these treatments have contributed to an increase in the number of patients experiencing renal impairment, mainly acute renal failure (ARF), caused by the physiological and haemodynamic stressors imposed by the hostile extrauterine environment. In such cases, clinical conditions include a low Apgar score, sepsis, therapeutic interventions, and various nephrotoxic drugs. ${ }^{2}$ Data in the literature on the incidence of ARF are extremely variable, mainly because of differences in the criteria used to define the disease, and range from $8 \%{ }^{3}$ to $24 \%{ }^{4}$ of all admissions to neonatal intensive care units (NICUs). Most of these conditions are transient and disappear after correction of the underlying derangement or disease, and Italian studies ${ }^{5} 6$ report similar values to those of Stapleton and coworkers. ${ }^{3}$ The main causes of ARF in the neonate are pre-renal mechanisms including hypovolaemia, hypotension, and hypoxaemia (more than $80 \%$ of cases). Intrinsic renal and post-renal failure are much rarer conditions (about $11 \%$ and $3 \%$ respectively). ${ }^{4}$

To investigate possible associations between a number of common therapeutic interventions, particularly drug treatments, and the risk of ARF in preterm newborns, we performed a case-control study among babies admitted to NICUs of several major hospitals in Italy over a period of three years. We used the standard $\operatorname{method}^{7}$ of selecting patients on the basis of their disease status (in our case preterm newborns with ARF) and comparing them with controls similar in all relevant ways except the disease. This is particularly suitable in our situation in which prematurity itself is a condition predisposing to ARF.

\section{METHODS}

\section{Study population}

The study population was preterm newborn infants of $<38$ weeks gestation receiving care in the NICU of one of seven Italian hospitals after approval of the ethics committees. Medical care in all NICUs was provided by neonatologists working under similar policies and in accordance with common practices. Neonates were enrolled after written informed consent had been obtained from their parents: eligible newborn infants with major congenital anomalies were excluded from the study.

From March 2000 to March 2003, potential cases of ARF were identified as the presence of high serum creatinine concentrations after the 60th hour of life (values of $\geqslant 114.92$ and $\geqslant 88.40 \mu \mathrm{mol} / \mathrm{l}$ were considered pathological in patients of $<33$ weeks and $\geqslant 33$ weeks respectively) with or without oliguria (urine output $<1 \mathrm{ml} / \mathrm{kg} / \mathrm{h}$ ) which may be absent in the first days of drug induced renal damage. ${ }^{8}$ Serum creatinine concentrations in the first two days of life were ignored as they reflect maternal values, ${ }^{9}$ whereas later persistent elevation of serum creatinine concentration is widely accepted as a diagnostic criterion of ARF. ${ }^{8}$ The first day on which the serum creatinine concentration was considered pathological was defined as the index date.

Abbreviations: ARF, acute renal failure; $\mathrm{NICU}$, neonatal intensive care unit; PDA, patent ductus arteriosus 


\begin{tabular}{|c|c|c|c|}
\hline Variable & $\begin{array}{l}\text { Cases } \\
(n=71)\end{array}$ & $\begin{array}{l}\text { Controls } \\
(n=101)\end{array}$ & p Value \\
\hline Male & $39(55 \%)$ & $62(61 \%)$ & 0.491 \\
\hline Gestational age (weeks) & $27.83(3.63)$ & $28.89(3.67)$ & NS \\
\hline$<25$ weeks & $12(17 \%)$ & $11(11 \%)$ & 0.361 \\
\hline $25-28$ weeks & $34(48 \%)$ & $42(42 \%)$ & 0.507 \\
\hline 29-32 weeks & $14(20 \%)$ & $27(27 \%)$ & 0.378 \\
\hline$>32$ weeks & $11(15 \%)$ & $20(20 \%)$ & 0.601 \\
\hline Birth weight (g) & $1115.98(572.36)$ & $1275.55(626.63)$ & NS \\
\hline$<800 \mathrm{~g}$ & $25(35 \%)$ & $24(24 \%)$ & 0.143 \\
\hline $800-1500 \mathrm{~g}$ & 31 (44\%) & $44(44 \%)$ & 0.886 \\
\hline $1500-2000 \mathrm{~g}$ & $6(8 \%)$ & $16(16 \%)$ & 0.231 \\
\hline$>2000 \mathrm{~g}$ & $9(13 \%)$ & $16(16 \%)$ & 0.719 \\
\hline SGA & $9(13 \%)$ & $14(14 \%)$ & 0.998 \\
\hline \multicolumn{4}{|l|}{ Apgar score } \\
\hline lst min & $4.59(2.66)$ & $5.12(2.21)$ & NS \\
\hline 5th $\min$ & $7.03(1.84)$ & $7.28(1.79)$ & NS \\
\hline
\end{tabular}

Matching of controls (two neonates for each case) was subsequently performed according to the following criteria: same sex as the case, with a birth weight within $100 \mathrm{~g}$ of the case and a gestational age within one week of the case. Information on controls was taken into account at the same day interval from birth to the index date of the matched case.

\section{Data collection}

Data were collected through detailed questionnaires especially designed for the study, including information on newborns and mothers, and entered into a computerised relational database (Microsoft Access).

Basic information, biological data, clinical outcomes diagnosed or suspected, and all therapeutic interventions (particularly drugs administered) were recorded for each newborn.

Mothers were interviewed by a trained doctor within a few days of the delivery. The study was explained and an information pamphlet was provided. They were then given time to decide whether or not to participate. Mothers who could not be interviewed in hospital were contacted by phone. Women were asked about previous obstetric history, their pregnancy, and intrapartum risk factors (including drugs administered). Information was also collected about sociodemographic variables and any family history of acute and chronic diseases, in particular those related to renal function.

\section{Renal function}

To test renal function during the observational period, serum creatinine concentrations, blood urea nitrogen and urine output of each patient were measured and recorded every two to three days throughout the first month of life. Oliguria was established on the basis of urine volumes measured over a period of 24 hours. In addition, all newborns had renal sonography examinations to evaluate the size, structure, and echogenicity of the kidneys.

\section{Statistical analysis}

The research was designed and analysed as a case-control study. Statistical analysis was performed using the Statistical Package for Social Sciences for Windows (SPSS Inc, Chicago, Illinois, USA).

Univariate analysis was performed to identify differences between the case and the control groups using Student's $t$ test (continuous data) or the $\chi^{2}$ test (categorical variables) as

Table 2 Maternal characteristics: information about pregnancy and delivery

\begin{tabular}{llll}
\hline & $\begin{array}{l}\text { Cases } \\
\text { Variable }\end{array}$ & $\begin{array}{l}\text { Controls } \\
(\mathbf{n}=101)\end{array}$ & p Value \\
\hline Age & $31.03(5.64)$ & $31.92(4.73)$ & NS \\
Renal pathologies before pregnancy & $10(14 \%)$ & $7(7 \%)$ & 0.198 \\
Renal pathologies during pregnancy & $4(6 \%)$ & $9(9 \%)$ & 0.612 \\
Primiparity & $23(32 \%)$ & $36(36 \%)$ & 0.780 \\
Smoking during pregnancy & $8(11 \%)$ & $6(6 \%)$ & 0.330 \\
Alcohol during pregnancy & $17(24 \%)$ & $17(17 \%)$ & 0.338 \\
Pre-eclampsia & $8(11 \%)$ & $21(21 \%)$ & 0.159 \\
Premature rupture of membranes & $22(31 \%)$ & $20(20 \%)$ & 0.133 \\
Maternal fever & $12(18 \%)$ & $8(8 \%)$ & 0.117 \\
Caesarean section & $53(75 \%)$ & $66(65 \%)$ & 0.257 \\
Fetal problems & $31(44 \%)$ & $27(27 \%)$ & 0.032 \\
Maternal problems & $22(31 \%)$ & $39(39 \%)$ & 0.386 \\
Twins & $18(25 \%)$ & $14(14 \%)$ & 0.088 \\
Drugs during pregnancy & $53(75 \%)$ & $62(62 \%)$ & 0.039 \\
Antibiotics & $23(32 \%)$ & $13(13 \%)$ & 0.004 \\
NSAIDs & $25(37 \%)$ & $19(19 \%)$ & 0.013 \\
Steroids & $22(31 \%)$ & $25(25 \%)$ & 0.466 \\
Drugs during delivery & $60(84 \%)$ & $68(68 \%)$ & 0.018 \\
Antibiotics & $21(30 \%)$ & $14(14 \%)$ & 0.020 \\
Steroids & $3(4 \%)$ & $3(3 \%)$ & 0.984 \\
\hline Values are mean (SD) or number (\%). & & & \\
NSAID, Non-steroidal anti-inflammatory & & & \\
& & & \\
\hline
\end{tabular}


Table 3 Therapeutic interventions, diagnosed diseases, and drug treatments before onset of acute renal failure

\begin{tabular}{llll} 
& $\begin{array}{l}\text { Cases } \\
\text { (n=71) }\end{array}$ & $\begin{array}{l}\text { Controls } \\
(\mathbf{n}=101)\end{array}$ & p Value \\
\hline Endotracheal intubation & $60(85 \%)$ & $70(69 \%)$ & 0.035 \\
At birth & $46(65 \%)$ & $47(46 \%)$ & 0.027 \\
Subsequently & $14(20 \%)$ & $23(23 \%)$ & 0.771 \\
Percutaneous venous catheter & $40(56 \%)$ & $36(36 \%)$ & 0.011 \\
Duration of use (days) & $18.02(16.00)$ & $17.61(15.57)$ & $\mathrm{NS}$ \\
Umbilical artery catheter & $57(80 \%)$ & $81(80 \%)$ & 0.856 \\
Duration of use (days) & $7.58(4.39)$ & $6.26(2.51)$ & 0.013 \\
Central venous catheter & $13(18 \%)$ & $21(21 \%)$ & 0.835 \\
Duration of use (days) & $14.69(11.25)$ & $21.28(11.26)$ & $<0.001$ \\
Meconium stained amniotic fluid & $16(23 \%)$ & $9(9 \%)$ & 0.023 \\
Hyperbilirubinaemia & $60(85 \%)$ & $80(79 \%)$ & 0.496 \\
Phototherapy & $59(83 \%)$ & $68(68 \%)$ & 0.032 \\
Low Apgar score & $30(42 \%)$ & $27(27 \%)$ & 0.049 \\
Respiratory distress syndrome & $63(89 \%)$ & $83(82 \%)$ & 0.334 \\
Mechanical ventilation & & & \\
$\quad$ Frequency & $58(82 \%)$ & $73(72 \%)$ & 0.213 \\
Length (days) & $13.38(15.07)$ & $13.99(16.07)$ & $\mathrm{NS}$ \\
Oxygen supplementation & $8(11 \%)$ & $1(1 \%)$ & 0.008 \\
Surfactant requirement & $52(73 \%)$ & $61(60 \%)$ & 0.113 \\
Patent ductus arteriosus & $31(44 \%)$ & $28(28 \%)$ & 0.049 \\
Sepsis & $16(23 \%)$ & $18(18 \%)$ & 0.569 \\
\hline Values are mean (SD) or number (\%). & & & \\
\hline
\end{tabular}

appropriate: statistical significance was defined as $\mathrm{p} \leqslant 0.05$. Odds ratio (OR) and $95 \%$ confidence interval (CI) were calculated for each $2 \times 2$ table. Variables that the univariate analysis showed to be significant were entered into a stepwise logistic regression model.

\section{RESULTS}

The study population included 81 consecutive cases of ARF (mainly identified on the third or fourth day of life) in preterm infants in NICUs. Six subjects were excluded from the study because of difficulty collecting information about the mothers. The parents of four newborns refused to participate. The control group consisted of 101 rather than 142 newborn infants, because it was not always possible, according to our criteria, to locate a second control for cases of low gestational age $(<25$ weeks $)$.

As reported in table 1, the mean gestational age and birth weight of our 71 preterm infants with ARF were 27.83 (3.63) weeks and 1115.98 (572.36) g respectively. Very low birthweight infants (birth weight $<1500$ g) made up $79 \%$ (56/71) of the neonates. In addition to gestational age and birth weight, cases and controls were comparable with regard to Apgar scores, baseline mean highest ( 51.14 (12.54) v 50.98 $(10.51) \mathrm{mm} \mathrm{Hg})$ and lowest $(28.62 \quad(10.04) \quad v \quad 28.42$ $(8.68) \mathrm{mm} \mathrm{Hg}$ ) blood pressure and respiratory variables $\left(\mathrm{FIO}_{2} 49.59\right.$ (24.80) v 47.89 (22.48)\%; $\mathrm{PaO}_{2} 55.72$ (22.50) $v$ $61.06 \quad(22.38) \mathrm{mm} \mathrm{Hg} ; \quad \mathrm{PaCO}_{2} \quad 43.21 \quad(10.13) \quad v \quad 43.76$ (9.81) $\mathrm{mm} \mathrm{Hg}$ ), observed at the beginning of pharmacological treatments in the cases and on the same postnatal days in the controls.

The results of the univariate analysis show the differences between cases and controls (tables 2-5) and the relative OR with 95\% CI (table 6).

The data on pregnancy and delivery (table 2) show some significant differences between mothers of case subjects and controls in relation to drugs administered during pregnancy (antibiotics and NSAIDs) and delivery (antibiotics).

Therapeutic interventions such as endotracheal intubation at birth, catheterisation, phototherapy, and oxygen supplementation were more often applied to case subjects than controls. Moreover, a low Apgar score and patent ductus arteriosus (PDA) were diagnosed in a significantly greater percentage of preterm infants with ARF (table 3). Significant differences were also observed in relation to presence of meconium stained amniotic fluid between cases and controls.

\begin{tabular}{|c|c|c|c|}
\hline & $\begin{array}{l}\text { Cases } \\
(n=71)\end{array}$ & $\begin{array}{l}\text { Controls } \\
(n=101)\end{array}$ & $p$ Value \\
\hline Antibiotics & $61(86 \%)$ & $87(86 \%)$ & 0.856 \\
\hline Aminoglycosides & $50(70 \%)$ & $80(79 \%)$ & 0.254 \\
\hline Duration of use (days) & $6.35(3.82)$ & $6.46(4.33)$ & NS \\
\hline Penicillins & $55(77 \%)$ & $79(79 \%)$ & 0.877 \\
\hline Duration of use (days) & $7.09(3.19)$ & $7.63(3.90)$ & NS \\
\hline Cephalosporins & $14(19 \%)$ & $5(5 \%)$ & 0.001 \\
\hline Duration of use (days) & $8.51(3.99)$ & $7.20(3.20)$ & 0.018 \\
\hline Glycopeptides & $2(2.8 \%)$ & $4(4 \%)$ & 0.984 \\
\hline Duration of use (days) & $10.50(7.78)$ & $17.50(9.33)$ & $<0.001$ \\
\hline Macrolides & $5(7 \%)$ & $7(7 \%)$ & 0.783 \\
\hline Duration of use (days) & $5.60(0.89)$ & $4.60(1.34)$ & $<0.001$ \\
\hline Ibuprofen & $22(31 \%)$ & $17(17 \%)$ & 0.046 \\
\hline Furosemide & $17(24 \%)$ & $11(11 \%)$ & 0.038 \\
\hline Dopamine & $41(58 \%)$ & $62(62 \%)$ & 0.576 \\
\hline
\end{tabular}


Table 5 Renal outcome

\begin{tabular}{|c|c|c|}
\hline Variable & $\begin{array}{l}\text { Cases } \\
(n=71)\end{array}$ & $\begin{array}{l}\text { Controls } \\
(n=101)\end{array}$ \\
\hline \multirow{2}{*}{\multicolumn{3}{|c|}{ Blood urea nitrogen $(\mathrm{mmol} / \mathrm{l})$}} \\
\hline & & \\
\hline Day 2 & $7.18(5.56)$ & $4.03(2.68)^{\star \star * *}$ \\
\hline Day 4 & $8.92(6.93)$ & $3.86(2.40)^{* * *}$ \\
\hline Day 7 & $9.04(8.23)$ & $3.48(2.41)^{* * *}$ \\
\hline Day 10 & $7.05(6.12)$ & $3.64(2.70)^{* * *}$ \\
\hline Day 14 & $4.42(4.54)$ & $2.62(2.64)^{* \star \star}$ \\
\hline Day 21 & $4.14(4.63)$ & $2.81(2.80)^{*}$ \\
\hline Day 28 & $2.51(2.70)$ & $1.91(2.26)$ \\
\hline \multicolumn{3}{|l|}{ Serum creatinine $(\mu \mathrm{mol} / \mathrm{l})$} \\
\hline Day 2 & $129.95(37.13)$ & $79.56(17.68)^{* * *}$ \\
\hline Day 4 & $143.21(39.78)$ & $73.37(20.33)^{\star \star \star *}$ \\
\hline Day 7 & $137.91(45.08)$ & $68.95(19.45)^{\star \star *}$ \\
\hline Day 10 & $113.15(37.13)$ & $66.30(17.68)^{\star \star \star *}$ \\
\hline Day 14 & $92.82(35.36)$ & $60.99(17.68)^{* * *}$ \\
\hline Day 21 & $81.33(32.71)$ & $57.46(22.98)^{* * *}$ \\
\hline Day 28 & $65.42(30.94)$ & $47.74(18.56)^{* * *}$ \\
\hline
\end{tabular}

If we consider drugs administered to our preterm infants in the first days of life-that is, before diagnosis of ARF (table 4) —cases received more drugs (cephalosporins, ibuprofen, and furosemide) often given in association and, in some situations, for a longer period of time. Single antibiotics, such as ceftazidime and ampicillin, were more often administered to case subjects.

Regarding the renal function tests shown in table 5, a greater percentage of oliguria $(8 \% \vee 1 \%)$ and significantly higher blood urea nitrogen concentrations were observed in cases than controls. Moreover, significantly higher levels of serum creatinine were persistent in cases throughout the first month of life. The other routine biochemical and haematological variables showed no significant differences between the two study groups.

Kidneys were within the normal range for size and shape. Compared with controls, a significantly higher percentage of preterm infants of the case group showed medullary hyperechogenicity $\left(25 \%(18 / 71)\right.$ v $5 \%(5 / 101) ; \chi^{2}=13.271$, $\mathrm{p}<0.001)$. A similar percentage of neonates with a mild urinary tract dilatation (pyelectasis) was observed in the two groups $(7 \%(5 / 71)$ v $5 \%(5 / 101))$.

Rates of survival at one month were divergent in the two groups, with an $11 \%$ mortality in the case group compared with a $2 \%$ mortality in the control group. The most common causes of death were overwhelming sepsis (six cases) and necrotising enterocolitis (two cases).

\begin{tabular}{|c|c|c|}
\hline & OR & $95 \% \mathrm{Cl}$ \\
\hline Drugs during pregnancy & 1.998 & 1.016 to 3.930 \\
\hline Antibiotics & 2.299 & 1.043 to 5.069 \\
\hline NSAIDs & 2.346 & 1.168 to 4.710 \\
\hline Drugs during delivery & 2.647 & 1.231 to 5.692 \\
\hline Antibiotics & 2.610 & 1.220 to 5.583 \\
\hline Endotracheal intubation & 2.114 & 1.132 to 3.948 \\
\hline Percutaneous catheter & 2.433 & 1.305 to 4.536 \\
\hline Phototherapy & 2.386 & 1.130 to 5.037 \\
\hline Low Apgar score & 2.005 & 1.052 to 3.822 \\
\hline \multicolumn{3}{|l|}{ Drugs given to the newborns } \\
\hline Ceftazidime & 4.716 & 1.614 to 13.782 \\
\hline Ampicillin & 2.156 & 1.143 to 4.069 \\
\hline Ibuprofen & 2.218 & 1.075 to 4.578 \\
\hline Furosemide & 2.576 & 1.123 to 5.907 \\
\hline Medullary hyperechogenicity & 4.360 & 1.919 to 9.906 \\
\hline
\end{tabular}

The multivariate logistic regression analysis included all variables with $\mathrm{p}<0.05$ observed in the univariate analysis (drugs given to the mothers during pregnancy and the delivery, endotracheal intubation, percutaneous catheter, phototherapy, low Apgar score, drugs given to the newborns, medullary hyperechogenicity). Table 7 shows the results. Ceftazidime administration (OR 5.082; 95\% CI 1.493 to 17.297) and medullary hyperechogenicity (OR 4.491; 95\% CI 1.879 to 10.731 ) were associated with a greater risk of ARF, whereas for the other variables (low Apgar score, ampicillin, ibuprofen) the risk was lower.

\section{DISCUSSION}

Few data are available on ARF in the neonatal period, particularly with regard to preterm infants with a low gestational age. It is also difficult to compare information because of differences in the populations examined and the criteria used to estimate renal function.

This is the first study in which case and control subjects were closely matched for gestational age and birth weight, minimising the confounding effects of these factors. Moreover, with our study it has been possible to quantify all risk factors involved in ARF development in a population of preterm newborns on the basis of multiple sources of information, including maternal interviews. Previous studies have generally lacked a comparison group or maternal information $^{10} 11$ which may be important for elucidating other possible risks such as prenatal drugs.

From the analysis of the non-clinical characteristics of our premature infants, it emerges that a very low birthweight infant is at specific risk of ARF (79\% of our case subjects weighed $<1500 \mathrm{~g}$ at birth), and this may explain the

Table 7 Results of multivariate logistic regression analysis of risk factors for development of acute renal failure

\begin{tabular}{lll}
\hline Variable & OR & $95 \% \mathrm{Cl}$ \\
\hline Low Apgar score & 2.143 & 1.065 to 4.313 \\
Medullary hyperechogenicity & 4.491 & 1.879 to 10.731 \\
Ampicillin & 2.368 & 1.098 to 5.104 \\
Ceftazidime & 5.082 & 1.493 to 17.297 \\
lbuprofen & 2.885 & 1.229 to 6.775 \\
\hline
\end{tabular}


problems that we encountered in identifying matched controls with the same characteristics as the case subjects but without renal problems, as also reported by Ojala et al. ${ }^{12}$ It also confirms that prematurity must be considered one of the main risk factors for ARF development. ${ }^{4}$

ARF was usually transient. In most cases, serum creatinine concentrations progressively decreased to normal over the first 14 days of life (93\%), persisting at high levels in only five cases $(7 \%)$ after one month. In these five patients, concentrations had returned to normal in the 2nd month of life. These data seem to confirm the pre-renal origin of $\mathrm{ARF}^{4}$ related to drugs, therapeutic interventions, or diseases which cause hypoperfusion of functioning kidneys. The condition is reversible in parallel with the resolution of the underlying problems or the suspension of certain treatments.

The ecographic data revealed no differences in the percentage of subjects with pyelectasis (a urinary tract dilatation rarely considered pathological and usually not requiring any particular therapeutic measure ${ }^{13}$ ), whereas a significantly higher percentage of cases showed medullary hyperechogenicity, generally considered an index of aspecific renal stress.

Analysis of information related to the mothers revealed distinct patterns of risk for certain antepartum and intrapartum variables. Case status was associated with drugs taken by the mothers during pregnancy (NSAIDs, antibiotics) or delivery (antibiotics), confirming the influence of maternal pharmacological treatments on the fetus or newborn. Several cases of severe and sometimes irreversible renal insufficiency have been described in neonates after prenatal exposure to NSAIDs. ${ }^{14-16}$ As far as antibiotics are concerned, it is known that $\beta$ lactams and aminoglycosides cross the placenta, and adverse renal effects have been observed in newborn animals. ${ }^{17} 18$

If we examine the therapeutic interventions applied to our preterm infants, intubation and catheterisation have also previously been indicated as risk factors for ARF development. ${ }^{2}$ In particular, the placement of arterial and venous catheters and duration of their use were found to be risk factors correlated with renal abnormalities. ${ }^{12}$ Phototherapy remains the standard treatment of hyperbilirubinaemia in newborns, ${ }^{19}$ even though hydration status should be monitored. It has been reported that this practice may cause renal problems in the newborn. ${ }^{2}$

As expected, a significant correlation was observed between ARF development and the presence of a low Apgar score and PDA. Although the data available in the literature on low Apgar scores are conflicting, our results are in agreement with those of Gouyon and Guignard, ${ }^{20}$ who reported a clear relation between renal problems and the presence of a low Apgar score. In the case of PDA diagnosis, its association with ARF development may be due to the disease itself, but also to its treatment. In fact, a severe PDA causes hypovolaemia, predisposing the newborn to renal problems. ${ }^{2}$ Moreover, during significant left to right shunting through the open ductus, circulatory failure and large aortic run-off lead to a decreased renal perfusion with subsequent stimulation of the renin-angiotensin system. Thus renal perfusion becomes dependent on the release of vasodilating prostaglandins. Consequently, administration of NSAIDs results in decreased renal perfusion and urine output. ${ }^{21}$

Respiratory distress syndrome is considered one of the main causes of pre-renal failure, as it reduces glomerular filtration rate and renal plasma flow. ${ }^{4}$ The percentage of respiratory distress syndrome was not significantly different between our two groups. Rather, we observed a significant difference between cases and controls with regard to the severity of the disease, accounted for by the greater percentage of treatments and complications observed in neonates with ARF. This correlates well with the fact that an effect of respiratory distress syndrome on renal function in neonates is the inability to maintain adequate adjustment of circulatory and respiratory functions. ${ }^{4}$

Finally, drug toxicity is involved in $50 \%$ of ARF cases in preterm infants, ${ }^{22}$ determining both intrinsic and pre-renal failure from vasoconstriction. As confirmed by our data, this is particularly true for NSAIDs and diuretics. These drugs, often used in premature newborns in the treatment of PDA and in fluid/electrolyte management respectively, can directly affect renal function. Their mechanism of action implies inhibition of vasodilating prostaglandins and stimulation of the vasoconstricting renin-angiotensin system. ${ }^{12} 2324$

In many NICUs, antibiotics are often prescribed in the first days of life to prevent or cure early and late onset sepsis caused by maternal infections or invasive devices such as central catheter positioning or endotracheal intubation, and contrasting data exist on their nephrotoxicity. ${ }^{10} 2526$ In our neonates with ARF, we found a significantly greater use of ceftazidime and ampicillin, whereas aminoglycosides and glycopeptides (potentially nephrotoxic) were administered in a similar manner to both case subjects and controls. Another factor to be considered in our cases was the longer duration of cephalosporin treatment, even in the presence of negative cultures, despite international recommendations that treatments should be prolonged in the presence of proven infection. ${ }^{27}$

The multivariate analysis confirmed the association between some drugs (particularly ceftazidime, but also ibuprofen) and ARF development in very low birthweight infants with a predisposing situation of aspecific renal stress such as medullary hyperechogenicity. The low glomerular filtration rate of the neonatal kidney, sufficient for growth under normal conditions, limits the postnatal renal functional adaptation to endogenous and exogenous stress. Such stress may take the form, in our case subjects, of a low Apgar score and exposure to drugs. This condition becomes even more problematic when these factors occur in combination.

Data on survival of preterm infants are extremely variable, depending mainly on gestational age and birth weight of the subjects and the period of observation. In our study, the observed percentages are comparable to the results of other studies in Western countries. ${ }^{28}{ }^{29}$ However, attention should be paid to the different survival rates observed in our two groups. Even though the causes of death were various, renal problems and risk factors evident in this study may also have contributed to the lower percentage survival of our case subjects. Therefore, even though ARF is usually reversible in these subjects, as also confirmed by our data, attention should be paid to preterm newborns who experience a slight increase in serum creatinine. Careful monitoring is necessary, as this condition is not rare in NICUs, and the line between normality and ARF is very thin in the first days of life. Given that long term studies do not exist and renal insufficiency may amplify other common diseases observed in preterm infants, it is important, in our opinion, to underline the multifactorial origin of ARF, as some risk factors such as a low Apgar score cannot be prevented, whereas iatrogenic effects from drug treatments could be avoided. ${ }^{30}$

\section{ACKNOWLEDGEMENTS}

Special thanks go to B Pinna, M Di Marzio, E Barbante, M R Ziccardi, M Perin, P Tramontozzi, P Tonetto, S Borgione (members of the Neonatal Nephrology Study Group of the Italian Society of Neonatology), who were so helpful in the acquisition of data. This study was partly funded by MIUR $60 \%$ grants (University of Sacred Heart, Roma). Some of the data have been presented in the poster session at the Pediatric Academy Societies Annual Meeting of May 2005. 


\section{What is already known on this topic}

- Acute renal failure in the newborn is a common problem mainly due to hypoxic ischaemic injury and/ or toxic insults, but few data are available because of the difficulty of comparing information

- Such alterations in renal function are often reversible and recovery is highly dependent on the underlying causes and prompt and correct therapeutic intervention.

\section{What this study adds}

- This case-control study, by using multiple sources of information including maternal data, shows a multifactorial origin of acute renal failure in the newborn

- The multivariate logistic regression analysis underlines that some risk factors observed in our preterm neonates, such as iatrogenic effects from drug treatments, could be avoided

\section{Authors' affiliations}

L Cataldi, Department of Pediatrics, University of Sacred Heart, Rome, Italy

R Leone, U Moretti, L Cuzzolin, Department of Medicine and Public Health, Section of Pharmacology and Clinical Pharmacology Unit, University of Verona, Verona, Italy

B De Mitri, Pediatric Division, Section of Neonatal Intensive Care Unit, A Di Summa Hospital, Brindisi, Italy

V Fanos, L Ruggeri, Department of Pediatrics and Clinical Medicine, Section of Neonatal Intensive Care Unit, University of Cagliari, Cagliari, Italy

G Sabatino, Neonatal Intensive Care Unit, University G D’Annunzio, Chieti, Italy

F Torcasio, Neonatal Intensive Care Unit, Niguarda Ca' Granda Hospital, Milano, Italy

V Zanardo, Pediatric Division, University of Padova, Padova, Italy

G Attardo, Neonatal Unit, Civic Hospital, Palermo, Italy

F Riccobene, Neonatology Division, Neonatal Intensive Care Unit, S

Camillo Hospital, Roma, Italy

C Martano, Neonatal Pathology Division, University of Torino, Torino, Italy

D Benini, Pediatric Division, Negrar Hospital, Verona, Italy

Competing interests: none declared

\section{REFERENCES}

1 Tommiska V, Heinonen K, Ikonen S, et al. A nationwide short-term follow-up study of extremely low birth weight infants born in Finland in 1996-1997. Pediatrics 2001; 107:1-9.
2 Toth-Heyn P, Drukker A, Guignard JP. The stressed neonatal kidney: from pathophysiology to clinical management of neonatal vasomotor nephropathy.
Pediatr Nephrol 2000;14:227-39.

3 Stapleton FB, Jones DP, Green RS. Acute renal failure in neonates: incidence, etiology and outcome. Pediatr Nephrol 1987;1:314-20.

4 Hentschel R, Lödige B, Bulla M. Renal insufficiency in the neonatal period. Clin Nephrol 1996;46:54-8.

5 Satolli E. Treatment of acute renal failure in newborn: the neonatological approach. Riv ltal Pediatr 1994;20:328-30.

6 Montini G, Barbieri P, Zaramella P, et al. Epidemiology of acute renal failure in the neonatal period. It J Pediatr 1995;21:2-6.

7 Schulz KF, Grimes DA. Case-control studies: research in reverse. Lancet 2002;359:431-4.

8 Fanos V, Khoory BJ, Cataldi L. Postischaemic acute renal failure in newborns: physiopathological aspects and early diagnosis. In: Cataldi L, Fanos V, Simeoni U, eds. Neonatal nephrology in progress. Lecce: Agorà, 1996:237-49.

9 Gordjani N, Burghard R, Leititis JU, et al. Serum creatinine and creatinine clearance in healthy neonates and prematures during the first 10 days of life. Eur J Pediatr 1998; 148:143-5.

10 Bhatt-Mehta V, Schumacher RE, Faix RG, et al. Lack of vancomycinassociated nephrotoxicity in newborn infants: a case-control study. Pediatrics 1999;103:e48.

11 Abitbol CL, Baver CR, Montanè B, et al. Long-term follow-up of extremely low birth weight infants with neonatal renal failure. Pediatr Nephrol 2003; 18:887-93.

12 Ojala R, Ala-Houhala M, Ahonen S, et al. Renal follow-up of premature infants with and without perinatal indomethacin exposure. Arch Dis Child Fetal Neonatal Ed 2001;84:F28-33.

13 Fanos V, Agostiniani R, Cataldi L. Pyelectasis and hydronephrosis in the newborn and infant. Acta Paediatr 2000;89:900-4.

14 Peruzzi L, Gianoglio B, Porcellini MG, et al. Neonatal end-stage renal failure associated with maternal ingestion of cyclo-oxygenase-typel selective inhibitor nimesulide as tocolytic. Lancet 1999;354:1615.

15 Holmes RP, Stone PR. Severe oligohydramnios induced by cyclooxygenase-2 inhibitor nimesulide. Obstetr Gynecol 2000;96:810-1.

16 Cuzzolin L, Dal Cerè M, Fanos V. NSAID-induced nephrotoxicity from the foetus to the child. Drug Saf $2001 ; 24: 9-18$.

17 Smaoui H, Mallie P, Cheignon M, et al. Glomerular alterations in rat neonates after transplacental exposure to gentamicin. Nephron 1991;59:626-31.

18 Nathanson S, Moreau E, Merlet-Benichou C, et al. In utero and in vitro exposure to $\beta$-lactams impair kidney development in the rat. J Am Soc Nephrol 2000;11:874-84.

19 Dennery PA, Seidman DS, Stevenson DK. Neonatal hyperbilirubinemia. N Engl J Med 2001;344:581-90.

20 Gouyon JB, Guignard JP. Management of acute renal failure in newborns. Pediatr Nephrol 2000; 14:1037-44.

21 Leonhardt A, Seyberth HW. Do we need another NSAID instead of indomethacin for treatment of ductus arteriosus in preterm infants? Acta Paediatr 2003;92:996-9.

22 Simeoni U, Matis J, Messer J. Clinical implications of renal immaturity in tiny, premature infants. In: Cataldi L, Fanos V, Simeoni U, eds. Neonatal nephrology in progress. Lecce: Agorà, 1996:129-40.

23 Schlondorff D. Renal complications of nonsteroidal drugs. Kidney Int 1993;44:643-53.

24 Norwood VF, Tufro-McReddie A, Gomez RA. Development of the reninangiotensin system. In: Polin RA, Fox WW, eds. Fetal and neonatal physiology. Philadelphia: WB Saunders, 1998.

25 Sakata H, Maruyama S, Ishioka T, et al. Change of renal function during vancomycin therapy in extremely low birth weight infants. Acta Paediatr Jpn 1996;38:619-21.

26 Linder N, Edwards R, McClead R. Safety of vancomycin with or without gentamicin in neonates. Neonatal Netw 1993;12:27-30.

27 Isaacs D. Rationing antibiotic use in neonatal units. Arch Dis Child Fetal Neonatal Ed 2000;82:F1-2.

28 Stoll BJ, Hansen N, Fanaroff AA, et al. Late-onset sepsis in VLBW neonates: the experience of the NICHD Neonatal Research Network. Pediatrics 2002;110:285-91

29 Linder N, Haskin $O$, Levit $O$, et al. Risk factors for intraventricular haemorrhage in very low birth weight premature infants: a retrospective casecontrol study. Pediatrics 2003;111:e590.

30 Fanos V, Cataldi L. Antibacterial-induced nephrotoxicity in the newborn. Drug Saf 1999;20:245-67. 